\title{
O Perfil e a FormaÇão do Administrador Público: UMA Análise Curricular de Cursos de Graduação e Pós-Graduação DO BRASIL
}

\author{
The Public Manager's Profile and Education: A \\ CURRICULAR ANALYSIS OF UNDERGRADUATE AND GRADUATE COURSES \\ INBRAZIL
}

\begin{abstract}
VANESSA BRULON SOARES (vanessabrulon@gmail.com)
FundaÇÃo Getúlio Vargas - Escola Brasileira de AdMinistração PÚBLICA E DE EMPRESAS
\end{abstract}

Pierre OHAYON

UNIVERSIDADE FEDERAL DO RIO DE JANEIRO

GERSON ROSENBERG

FUNDAÇÃO OSWALDO CRUZ

\section{RESUMO}

O objetivo deste artigo é identificar em que pontos os cursos de graduação e pós-graduação em Administração Pública do Brasil atendem ao perfil desejado do administrador público traçado pela literatura especializada. Para tal, foram estabelecidos a definição e o papel do administrador público, bem como o percurso histórico da administração pública no Brasil. Além disso, foram analisados o perfil e a formação do administrador público, considerados mais adequados pela literatura especializada. Para atingir o referido objetivo foi realizada pesquisa bibliográfica e documental, comparando-se o currículo dos cursos de seis instituições de ensino superior do país com os dados levantados na literatura. Pode-se concluir que há uma correspondência dos currículos analisados com a literatura levantada no que diz respeito à presença de disciplinas referentes à política, gestão de pessoas, administração financeira, economia e novas tecnologias. Destacou-se, ainda, a divergência deste currículo com relação à bibliografia pesquisada no que se refere às disciplinas de ética, administração de recursos, relações internacionais, inovação, estratégia, gestão de mudanças, entre outras. Assim, espera-se que estes pontos de divergência aqui levantados possam servir de base para futuras discussões a respeito da formação do administrador público.

Palavras-Chave: administrador público; formação; cursos de administração pública. 


\section{ABSTRACT}

This paper aims at identifying how Brazilian undergraduate and graduate courses of public administration satisfy the expectations of public managers described by specialized literature. To this end, definition and role of public managers have been established, as well as a historical trajectory of public administration in Brazil. Moreover, the profile and education which are considered by specialized literature to be most adequate for public managers have been analyzed. In order to achieve such purpose, a bibliographic and documentary survey has been carried out comparing the curriculum of courses from six Brazilian higher education institutions with data gathered from the literature. From this analysis, it can be concluded that there is a correspondence between the examined curricula and the specialized literature regarding the presence of disciplines concerning politics, human relations, financial management, economics and new technologies. A divergence could also be observed between this curriculum and the bibliography analyzed related to disciplines such as ethics, resource management, international relations, innovation, strategy, change management, among others. Thus, it is expected that these points of divergence should serve as a basis for future discussions on the education of public managers.

Keywords: public manager; education; public administration courses.

\section{INTRODUÇÃO}

O administrador público assume papel fundamental diante da sociedade, por ser responsável pelo bom funcionamento das organizações públicas. Sendo assim, a formação deste profissional tem implicações diretas para o desenvolvimento do País. A administração pública hoje está consolidada como disciplina acadêmica, porém, como destaca Keinert (1996), existe uma tendência para questionar a existência de cursos de graduação em administração pública. Esta tendência carrega os resquícios de um período de severas críticas e questionamentos que tornaram extremamente desafiador o estabelecimento da administração pública no campo acadêmico. Assim, os cursos de graduação e pós-graduação em administração pública, que podem hoje ser encontrados no Brasil, sofreram algumas modificações durante o percurso turbulento a que esta disciplina se submeteu. Neste sentido, o presente artigo se propõe a 
realizar uma análise curricular de alguns cursos de administração pública, bem como da literatura especializada, para responder à seguinte questão: qual é o nível de desenvolvimento da administração pública brasileira hoje e que conhecimento e habilidades devem ser dominados pelo administrador público atual para torná-la mais eficiente?

Desta forma, o objetivo deste trabalho é identificar em que pontos os cursos de graduação e pós-graduação em administração pública do Brasil atendem ao perfil desejado do administrador público traçado pela literatura especializada.

Como objetivos específicos, destacam-se: (i) levantamento, fundamentado na literatura especializada, do perfil e formação mais adequados do administrador público para atuar nas organizações públicas atuais; (ii) análise dos currículos de alguns cursos de graduação e pósgraduação em administração pública do país; (iii) identificação dos pontos de similaridades entre os cursos, e em que pontos eles se diferenciam; (iv) identificação dos pontos de correspondência entre os currículos analisados e a demanda presente na literatura especializada; (v) oferecimento de material para uma reflexão no que diz respeito ao aprimoramento dos currículos atuais, com base nos resultados aqui obtidos.

Oliveira, Pereira e Ramirez (1995) esclarecem que não existe um perfil único que deva ser assumido pelo administrador engajado em função pública ou não. Isso se comprova ao se constatar que muitos empreendedores alcançaram grande sucesso sem ter conhecimento das técnicas ensinadas nos cursos de administração, consideradas necessárias para a formação do administrador ideal. Além disso, muitos cargos de gerenciamento são assumidos por profissionais de outras áreas, como engenheiros ou economistas, que nem sempre apresentam este conhecimento administrativo. Mas Oliveira, Pereira e Ramirez (1995) defendem que isso não deve desestimular a busca de melhor conhecimento sobre o trabalho do administrador, bem como suas habilidades e desempenho.

Há consenso entre os autores pesquisados com relação à relevância assumida pelo administrador público para o desenvolvimento socioeconômico do País. Além disso, estes autores revelam uma preocupação com as constantes mudanças sofridas pelas organizações públicas atualmente, bem como pela necessidade de que a formação destes profissionais esteja adequada a elas. A administração pública atual apresenta algumas deficiências que podem ser superadas com a melhor formação do administrador público. Segundo Penengo (1997), a 
administração pública atual pode ser caracterizada como rígida, burocrática e com pouco estímulo à inovação. Indo ao encontro de Penengo (1997), Dror (1997) acrescenta que a administração pública precisa assumir novas características modernas de gestão, onde também se percebe que existem grandes sinais de má gestão e até de corrupção. E ainda, Ferrarezi e Zimbrão (2005) defendem que o administrador público não está preparado para lidar com as frequentes mudanças que ocorrem no setor público.

Assim, o presente estudo procura levantar a discussão acadêmica com relação à boa formação do administrador público e à adequação dos currículos adotados pelos cursos de administração pública atuais.

\section{REFERENCIAL TEÓRICO}

Para que sejam eficientes e atendam satisfatoriamente à população, as organizações públicas brasileiras dependem fundamentalmente da qualidade de seus recursos humanos. Ao estabelecerem as funções das organizações públicas, os autores destacam o importante papel por elas desempenhado, o que revela a importância de uma boa formação por parte de seus funcionários.

Dias (1998 citado em PIRES; MACÊDO, 2006) afirma que o objetivo das organizações públicas é prestar serviço à sociedade, o que demonstra sua relevância. Dallari (1989) acrescenta que os funcionários públicos existem para atender a uma necessidade da população, já que a prestação de serviços públicos só pode ser feita por pessoas que são pagas pelo governo para tal. Porém, esta missão a eles atribuída cai em contradição com a limitação de recursos inerente a este tipo de organização. Assim, estas organizações cumprem a sua função ao buscarem maior eficiência da administração pública e o atendimento das necessidades da sociedade. De fato, o bem-estar da população depende da qualidade do serviço público a ela prestado, que por sua vez depende da eficiência de seus funcionários (DALLARI, 1989).

Dentro deste contexto, Dallari $(1989$, p. 11) ressalta que o que habitualmente se chama de "funcionário público" não está de acordo com a conceituação que a teoria e a lei estabelecem para esse conceito. A sociedade considera como funcionário público todo aquele que trabalha para o governo, incorrendo em distorções de interpretação. Para desfazer este equívoco, Dallari (1989) define cada um destes conceitos que se confundem. $\mathrm{O}$ autor apresenta três categorias distintas: agentes políticos, 
particulares que colaboram com o serviço público e servidores públicos. Porém, o administrador público ao qual se referirá o presente estudo se insere na categoria de servidor público, constituindo o funcionário que exerça tarefas administrativas ou, em alguns casos, gerenciais.

Sendo assim, para se caracterizar como um administrador público, o servidor deverá ocupar um cargo público, que pode ser definido como "o conjunto de atribuições e responsabilidades previstas na estrutura organizacional que devem ser cometidas a um servidor." (BRASIL, 1990, p. 1). Desta forma, o cargo público é o posto de trabalho ocupado pelo funcionário público (DALLARI, 1989).

Ressalta-se ainda, que os cargos públicos só podem ser criados por lei. Assim, somente a lei estabelece o número de cargos existentes em cada repartição, sua remuneração, as tarefas envolvidas e os requisitos que devem ser preenchidos para que se ocupe determinado cargo público. Um requisito que merece destaque é a aprovação em concurso público, exigido pela própria Constituição Federal (DALLARI, 1989).

Outro importante elemento que caracteriza o funcionário público diz respeito ao regimento ao qual está submetido. Enquanto trabalhadores do setor privado têm seu regime de trabalho definido pela Consolidação das Leis do Trabalho (CLT), os funcionários públicos têm seus direitos e deveres definidos por uma lei (Lei 8.112 de 11 de dezembro de 1990) chamada "Estatuto", por isso se diz que trabalham sob um regime estatutário. A CLT define um conjunto de direitos e deveres fundamentais do empregado e do empregador, porém deixa espaço para que as partes negociem entre si com relação à prestação do serviço e sua remuneração, resultando em um contrato de trabalho que só pode ser alterado por mútuo acordo entre as partes. Já no caso do regime estatutário, não há negociação nem contrato. As regras sob as quais o trabalho será prestado são definidas pela lei, só podendo ser alteradas por lei. No momento da posse de um determinado cargo público, o funcionário público manifesta automaticamente a aceitação das regras já estabelecidas em lei, que definem seus direitos e deveres no que diz respeito à prestação de seu serviço para a administração pública (DALLARI, 1989).

\section{O Percurso da Administração Pública no Brasil}

Pelo exposto anteriormente, fica clara a relevância do papel desempenhado pelo administrador público, assim como a importância de sua boa formação. Porém, apesar de hoje a administração pública ter um 
reconhecimento e seu espaço no campo acadêmico, o percurso para a sua consolidação apresentou muitos obstáculos.

É nos anos 1930, durante o primeiro governo Vargas, que tem início no Brasil a reforma burocrática que veio substituir a administração patrimonial na qual os patrimônios públicos e privados estavam fundidos, e o Estado era visto como propriedade do soberano (PEREIRA, 2009). A administração burocrática, "na época, era a melhor maneira de aumentar a eficiência, eliminar o nepotismo e reduzir a corrupção" (PEREIRA, 2009, p. 208). Porém, esta reforma que estabeleceu o serviço público profissional e os princípios da administração pública burocrática nunca foi concluída.

Com a ampliação da atuação do Estado como agente ativo no processo de desenvolvimento econômico do País, era preciso ter pessoal capacitado para realizar esta tarefa. Neste período foi criado o Departamento de Administração do Serviço Público (DASP) com o objetivo de auxiliar a modernização do estado, que passou a difundir a administração pública por meio de ações como a realização de concursos públicos, o desenvolvimento de carreiras e a divulgação de produção científica por meio da Revista do Serviço Público (GAETANI, 1999).

No pós-guerra, o ensino de administração pública na América Latina se expandiu devido ao aumento do mercado de trabalho no setor público e a maior preocupação com a capacitação de seus servidores. É dentro deste contexto que, em 1952, o ensino de administração pública como disciplina acadêmica foi introduzido no Brasil pela Fundação Getúlio Vargas (FGV), com a criação da Escola Brasileira de Administração Pública (EBAPE). Ademais, a cooperação técnica dos Estados Unidos da América (EUA) desempenhou um papel importante no estabelecimento e crescimento dos cursos de administração no Brasil.

Nos anos 1960, a administração pública como disciplina acadêmica se desenvolveu bastante no Brasil. Em 1967, ocorreram dois eventos importantes para a área que foram: a criação da Revista de Administração Pública (RAP), que se tornou o mais importante periódico da área, e a criação do programa de mestrado em administração pública, ambos pela FGV/EBAPE. Apesar disso, a área começou a declinar neste momento por questões políticas, como o advento da ditadura militar e o milagre econômico (GAETANI, 1999).

A partir daí, as instituições de ensino brasileiras acabaram optando, em sua maioria, pela adoção de currículos integrados, e a área de administração pública acabou sendo absorvida pela área de administração de empresas. O desestímulo do ensino de administração pública foi 
reforçado pela redução do estado nos anos 1980 devido à crise econômica e à estagnação (GAETANI, 1999). Porém, mesmo diante deste cenário, nos anos 1980, o governo do presidente Sarney promoveu a reforma administrativa para atender a demanda de reestruturação do estado, que tinha como um de seus objetivos capacitar o seu pessoal para atender às novas demandas da sociedade de forma mais eficiente. Para tal, em 1986, foi criada a Escola Nacional de Administração Pública (ENAP), uma escola de governo, com a missão de tornar a administração pública mais eficiente, por meio de formação adequada de seu pessoal (FERRAREZI; ZIMBRÃO, 2005).

Contudo, quando o Estado cresce, assumindo novos papéis sociais e econômicos e se constituindo como um Estado social-democrático, a administração burocrática deixa de ser eficiente. Ela se mostra incompatível com o capitalismo industrial, já que, neste caso, é essencial a separação entre Estado e mercado.

Assim, abre-se o caminho para a reforma da gestão pública, cujo objetivo básico era tornar a gestão pública mais eficiente e mais responsável. Esta reforma adota uma abordagem gerencial da administração pública, porque segue o modelo de gestão das empresas privadas, defendendo a maior autonomia e responsabilidade dos órgãos públicos, como forma de atingir maior eficiência e qualidade (PEREIRA, 2009). Foi introduzida, assim, a ideia de administração gerencial e a profissionalização para a transformação do modelo burocrático.

Ferrarezi e Zimbrão (2005) consideram que o setor público se torna cada vez mais complexo, exigindo, por isso, modificações na formação do administrador público, já que este não está preparado para enfrentar as constantes mudanças e novos desafios que se impõem.

Usando como indicar o crescimento do número de cursos de administração pública nos países pós-industriais, Gaetani (1999) avalia que o ensino da administração pública tem crescido em importância. Tal expansão, entretanto, não se dá apenas no nível de graduação. Vale ressaltar, ainda, o importante papel assumido pelos cursos de pósgraduação no País, nos últimos anos, suprindo a necessidade de profissionais que não tiveram a oportunidade de receber a formação básica em administração pública, devido à escassez do curso em tempos passados. A este respeito, Martins (2000), por exemplo, explica que os cursos de pós-graduação contribuíram significativamente para a institucionalização das pesquisas em universidades, ao contrário dos programas de graduação nos quais não foi possível estabelecer esta união entre ensino e pesquisa. Além disso, o autor diferencia os dois tipos de 
curso, ao caracterizar os cursos de pós-graduação como mais especialistas, oferecendo "um número limitado de disciplinas articuladas com as respectivas linhas de pesquisa dos cursos" (MARTINS, 2000, p. 55). Balbachevsky (2005) complementa esta ideia ao afirmar que os cursos de pós-graduação no Brasil possuem dificuldades quando têm uma tendência multidisciplinar, porque, em decorrência de problemas burocráticos, o sistema de avaliação da Capes tende a classificar este tipo de curso em notas baixas, estimulando sua especialização.

Com base em seus estudos, Keinert (1996, p. 21) conclui que as mudanças dos cursos de administração pública no Brasil estão fortemente correlacionadas com as mudanças nos paradigmas de administração pública. A autora, no entanto, defende que a interação entre a evolução da administração pública como campo de conhecimento. Ela sugere que o ensino de administração pública não acompanha as demandas do mercado profissional e isso também não ocorre nos cursos de mestrado. Mas, o processo de mudanças para a maior adaptação às demandas de mercado ocorre com mais facilidade nos cursos de pós-graduação, e por isso a atenção se deslocou para eles. O caminho da administração pública no Brasil descrito acima está sintetizado no Quadro 1.

Quadro 1: Percurso da Administração Pública no Brasil

\begin{tabular}{|c|c|c|}
\hline Ano & $\begin{array}{l}\text { Desenvolvimento do ensino de } \\
\text { Administração Pública no Brasil }\end{array}$ & $\begin{array}{c}\text { Contexto Histórico } \\
\text { Brasileiro } \\
\end{array}$ \\
\hline 1938 & Criação do DASP & $\begin{array}{l}\text { Estado Novo e ampliação } \\
\text { do papel do Estado }\end{array}$ \\
\hline $\begin{array}{c}\text { Década de } \\
1940\end{array}$ & $\begin{array}{l}\text { A administração pública como temática de } \\
\text { estudo é introduzida no Brasil }\end{array}$ & $\begin{array}{l}\text { Estado Novo e ampliação } \\
\text { do papel do Estado }\end{array}$ \\
\hline 1952 & $\begin{array}{l}\text { Criação da EBAPE, introduzindo o ensino de } \\
\text { administração pública no país }\end{array}$ & $\begin{array}{l}\text { Segundo governo Getúlio } \\
\text { Vargas }\end{array}$ \\
\hline $\begin{array}{c}\text { Década de } \\
1960\end{array}$ & $\begin{array}{l}\text { Expansão da administração pública como } \\
\text { disciplina acadêmica }\end{array}$ & Ditadura militar \\
\hline 1967 & $\begin{array}{l}\text { Criação da RAP e do programa de mestrado } \\
\text { em administração pública da FGV/EBAPE }\end{array}$ & Ditadura militar \\
\hline $\begin{array}{c}\text { Passagem } \\
\text { da década } \\
\text { de } 1960 \\
\text { para } 1970\end{array}$ & $\begin{array}{l}\text { Expansão do ensino de administração de } \\
\text { empresas }\end{array}$ & "Milagre econômico" \\
\hline $\begin{array}{l}\text { Década de } \\
1980 \\
\end{array}$ & $\begin{array}{l}\text { Desestímulo ao ensino de administração } \\
\text { pública }\end{array}$ & $\begin{array}{l}\text { Redução do Estado, crise } \\
\text { econômica e estagnação }\end{array}$ \\
\hline 1986 & Criação da ENAP & $\begin{array}{l}\text { Reforma administrativa do } \\
\text { governo Sarney }\end{array}$ \\
\hline
\end{tabular}




\section{O Perfil do Administrador Público}

No que diz respeito ao perfil do administrador público, requerido após as referidas mudanças, Oliveira, Pereira e Ramirez (1995) ressaltam que se tem associado à profissão do administrador habilidades extremamente diversificadas, que são consideradas fundamentais para o exercício de tal profissão. Isto se dá devido à diversidade de tarefas presentes no dia a dia do administrador, assim como pela grande amplitude de seu campo de atuação e de sua formação. Segundo Weber (1999), o funcionário na era moderna assume a posição pessoal de obediência à autoridade à qual está subordinado e este acaba tendo uma posição social distinta, dependendo do nível hierárquico que possuir. A influência dos certificados de formação aumenta conforme o nível hierárquico ocupado pelo indivíduo.

Souza (2002) considera que o gestor público mais adequado do administrador público no contexto atual, deve ter: iniciativa e criatividade; responsabilidade; capacidade de agir adequadamente diante de situações diversas; inteligência prática, voltada para a ação, desenvolvimento e aquisição de conhecimento, por meio de constante formação; capacidade empreendedora e de liderança; habilidades relacionamentos interpessoais; habilidades gerenciais; conhecimento especialista e generalista, conhecendo o particular baseado no geral.

Já para Keinert (1994 citado em FELISSICIMO, 1996), de acordo com o paradigma emergente, as habilidades que o administrador público deve dominar são: (i) habilidades humanas para que desenvolva sua capacidade de liderança, comunicação, negociação, administração de conflitos, adaptação a mudanças; (ii) habilidade profissional para que tenha uma visão estratégica, incentivando a criatividade e a inovação, e a capacidade técnica que lhe permita usar as tecnologias administrativas mais adequadas ao setor público; (iii) habilidade pública para que ele tenha responsabilidade social, noções de ética, democracia e compromisso com o serviço público.

Melo, Ckagnazaroff e Teodósio (2000) enfatizam este momento de mudança e afirmam que, diante de uma economia cada vez mais instável, as organizações buscam um quadro de funcionários mais enxuto e capaz de lidar com as mudanças de maneira ágil. Para tal, segundo os autores, estes profissionais devem ser mais flexíveis, com capacidade de negociação, e mais voltados para resultados. Também considerando o contexto atual, Pereira (2009) defende que, como a administração burocrática é incompatível com o capitalismo moderno, os contratos de trabalho devem ser mais flexíveis e os administradores públicos, mais 
profissionais, autônomos e competentes. Levando em consideração a reforma da gestão pública, que está preocupada com o caráter democrático das decisões, o autor ainda acrescenta que o administrador público deve realizar um processo decisório com maior transparência e responsabilização. A qualidade dessas decisões deve ser melhorada, e, para o autor, estas decisões se tornam mais competentes quanto mais descentralizados e autônomos forem os tomadores de decisão. Além disso, a reforma da gestão pública pretende dar mais autonomia aos administradores públicos, para que eles se tornem mais motivados a trabalhar criativamente.

\section{A formação do administrador Público}

Além do perfil adequado, o administrador público precisa receber boa formação que o torne capaz de responder adequadamente às demandas das organizações públicas atuais. A este respeito, muitos autores estabelecem o conhecimento que estes profissionais devem dominar. O Quadro 2 sintetiza o conhecimento mais relevante que deve ser dominado pelos administradores públicos, conforme apontado pela literatura especializada.

Como pode ser observado no Quadro 2, foi destacada em muitos trabalhos a necessidade do domínio de conhecimento não apenas técnico, mas também político, por parte do administrador que pretende atuar em organização pública. Souza (2002), Nicolini (2008), Felicíssimo (1996) e Gaetani (1999) defendem esta ideia e explicam que, como as organizações públicas são espaços de conflito político, onde as áreas política e administrativa se misturam, é necessário que haja gestores que tenham conhecimento técnico, mas também responsabilidade política.

Assim, esses autores defendem que o ensino de administração pública no Brasil deve conseguir conciliar a base prática requerida com conhecimento de natureza conceitual e abstrata, que também são necessários, dando destaque de modo equilibrado às questões políticas, sociais e administrativas. Seguindo este mesmo pensamento, Souza (1998) defende que disciplinas técnicas e de formação geral devem ser distribuídas de forma equilibrada na formação do administrador público, para que se possa enfocar questões sociais, políticas e administrativas em diferentes dimensões. É preciso formar administradores especialistas e generalistas em políticas públicas. 
Quadro 2: Conhecimento necessário ao Administrador Público

\begin{tabular}{|c|c|c|c|c|c|c|c|c|c|c|c|c|c|}
\hline Conhecimento & A1 & $\mathbf{A 2}$ & $\mathbf{A 3}$ & $\mathbf{A 4}$ & A5 & A6 & A7 & A8 & A9 & A10 & A11 & A12 & $\mathbf{A 1 3}$ \\
\hline Política & $\mathrm{X}$ & $\mathrm{X}$ & $\mathrm{X}$ & $\mathrm{X}$ & $\mathrm{X}$ & $\mathrm{X}$ & $\mathrm{X}$ & & & $\mathrm{X}$ & & & \\
\hline Direito & & & & & $\mathrm{X}$ & $\mathrm{X}$ & & & & & & & \\
\hline E̋tica & & & & & $\mathrm{X}$ & $\mathrm{X}$ & $\mathrm{X}$ & & & $\mathrm{X}$ & & $\mathrm{X}$ & $\mathrm{X}$ \\
\hline $\begin{array}{l}\text { Adm. de } \\
\text { Recursos }\end{array}$ & & & $\mathrm{X}$ & & $\mathrm{X}$ & $\mathrm{X}$ & & & & & & & \\
\hline Economia & & & & & $\mathrm{X}$ & $\mathrm{X}$ & & & & & & & \\
\hline $\begin{array}{l}\text { Gestão de } \\
\text { Pessoas }\end{array}$ & $\mathrm{X}$ & & & & $\mathrm{X}$ & & $\mathrm{X}$ & & & $\mathrm{X}$ & & & $\mathrm{X}$ \\
\hline Estratégia & $\mathrm{X}$ & & $\mathrm{X}$ & & $\mathrm{X}$ & & & & & & & & $\mathrm{X}$ \\
\hline $\begin{array}{l}\text { Finanças/ } \\
\text { Contabilidade }\end{array}$ & & & & & $\mathrm{X}$ & $\mathrm{X}$ & & & & & & & \\
\hline Negociação & & & & & $\mathrm{X}$ & & & & & & & & $\mathrm{X}$ \\
\hline Estatística & & & & & $\mathrm{X}$ & $\mathrm{X}$ & & & & & & & \\
\hline $\begin{array}{l}\text { Teorias } \\
\text { Organizacionais }\end{array}$ & & & & & & $\mathrm{X}$ & & & & & & & \\
\hline $\begin{array}{l}\text { Adm. } \\
\text { Internacional }\end{array}$ & & & & & & $\mathrm{X}$ & & & & $X$ & & & \\
\hline $\begin{array}{l}\text { Cultura } \\
\text { Nacional }\end{array}$ & & & & & & $\mathrm{X}$ & $\mathrm{X}$ & & & & & & \\
\hline Ciências Sociais & & & $\mathrm{X}$ & & & $\mathrm{X}$ & $\mathrm{X}$ & & & & & & \\
\hline Democracia & $X$ & & $\mathrm{X}$ & & & & $X$ & & & & & & $X$ \\
\hline Inovação & & & $\mathrm{X}$ & & & & $\mathrm{X}$ & & $\mathrm{X}$ & & $X$ & $X$ & $X$ \\
\hline $\begin{array}{l}\text { Gestão de } \\
\text { mudanças }\end{array}$ & $\mathrm{X}$ & & $\mathrm{X}$ & & & & & & & $\mathrm{X}$ & & & $\mathrm{X}$ \\
\hline Estágio & $\mathrm{X}$ & & $\mathrm{X}$ & & & & & & & & & & \\
\hline $\begin{array}{l}\text { Tecnologias/ } \\
\text { Informática }\end{array}$ & $\mathrm{X}$ & & & & & $\mathrm{X}$ & & $\mathrm{X}$ & $X$ & & & & \\
\hline
\end{tabular}

Legenda: A1: Souza (1998 e 2002); A2: Nicolini (2008); A3: Felicissimo (1996); A4: Gaetani (1999); A5: Newcomer (1999); A6: Duque (2006); A7: Ferrarezi e Zimbrão (2005); A8: Pacheco (2000); A9: Gomes (2008); A10: Penengo (1997); A11: Amaral (2006); A12: Dror (1997); A13: Keinert (1994).

Também esteve muito presente na literatura levantada, a ideia de que deve haver a clara distinção entre os cursos de administração pública e o de administração de empresas. A este respeito, Nicolini (2008) coloca que a administração pública se diferencia da administração de empresas por uma série de fatores, como a busca pela eficiência e não pelo lucro, e o tratamento justo de seus clientes, sem discriminá-los. Assim, para este autor, a simples aplicação das ferramentas de gestão empresarial em uma organização pública traz problemas, pois estas ferramentas são influenciadas pelos objetivos e formas das atividades empresariais, sendo muitas vezes inadequadas para as organizações públicas. Pode haver uma transposição destas ferramentas, mas é preciso respeitar as características 
da administração pública. Este pensamento deve se refletir na formação do administrador público, que deve ser capaz de estabelecer esta diferenciação.

Pereira (2009, p. 343) também vai ao encontro desta ideia ao defender que a gestão pública é essencialmente diferente da administração de empresas, já que essa última tem como mecanismo de coordenação o mercado e como principal objetivo o lucro, enquanto que na primeira este mecanismo é político e o objetivo é o interesse público. Por isso, segundo o autor, não se pode simplesmente levar as práticas e conceitos de um setor para o outro, deve-se "filtrar e reelaborar criticamente cada conceito, cada técnica" (PEREIRA, 2009, p. 343). Neste sentido, Newcomer (1999) ressalta a maior ligação do administrador público ao setor privado, devido à tendência de terceirização. Fundamentado nisso, ele defende que os administradores públicos devem ser bilíngues, o que significa dizer que eles devem estar cientes da terminologia usada tanto no setor privado, como no público.

É dentro deste contexto que Newcomer (1999) estabelece o conhecimento que ele considera de maior relevância para este profissional (Quadro 2). O autor enfatiza o direito e ética, que classifica como muito relevantes devido aos questionamentos da legitimidade do governo como prestador de serviço que são feitos atualmente. Também recebem destaque disciplinas que levem ao conhecimento da história e dos valores básicos desta profissão, para que com isso haja maior comprometimento com o serviço público. $O$ autor destaca também a administração de recursos, que, segundo ele, se tornou ainda mais desafiadora, já que, num ambiente de terceirização os arranjos de composição de custos são ainda mais complexos. Assim, os gerentes públicos devem ser capazes de evitar desperdícios.

Duque (2006) também é bastante específico ao delimitar as disciplinas que, para ele, devem estar presentes na formação dos administradores públicos. Assim, para o autor, é fundamental que os administradores públicos se familiarizem com as teorias organizacionais, que explicam os fenômenos de produtividade nas organizações, além de outros aspectos apresentados no Quadro 2. Para o autor, para que este profissional apresente um bom desempenho, é fundamental que ele saiba as principais características culturais e éticas de seus cidadãos. E ainda, deve saber usar bem os escassos recursos políticos. O autor também destaca como um conhecimento deve ser bem desenvolvido, o de ciência política, já que, nos países desenvolvidos, a administração pública é considerada um ramo da ciência política. 
A importância do conhecimento político também é observada nas ideias de Pereira (2009), que defende que o administrador público é também um agente político que exerce um papel político. O administrador público não assume o papel de apenas executar as políticas públicas desenvolvidas pelos políticos, mas também contribui para sua formulação. Baseado na reforma, ele é mais chamado a agir politicamente. $\mathrm{O}$ autor ainda destaca que essa abordagem política da reforma da gestão pública também exige um comportamento ético por parte dos administradores públicos.

Ferrarezi e Zimbrão (2005, p. 12) também propõem o que para eles seria a formação mais adequada do administrador público, com base na transmissão do conhecimento apresentado no Quadro 2. Os autores destacam a importância da gestão de pessoas que, para eles, deve ser um conhecimento dominado por todo administrador público e não apenas pela área de recursos humanos, já que investir em pessoas é o mais importante meio para mudanças nas organizações.

Já para Felicissimo (1996), estes profissionais devem estimular a inovação, a capacidade técnico-analítica e a compreensão políticoestratégica. $\mathrm{O}$ autor defende que, no contexto atual, é preciso que haja administradores públicos capazes de administrar democraticamente, permitindo a participação da comunidade. Para tal, o autor levanta o conhecimento que o administrador público deve adquirir em sua formação, como apresentado no Quadro 2. Felicissimo (1996) ainda destaca que a formação que os administradores públicos recebem leva-os a enfatizarem as dimensões operacionais e tácitas, em detrimento das dimensões social e estratégica das organizações públicas que, na visão do autor, também são fundamentais.

Outra disciplina de destaque foi a gestão de mudanças. A este respeito, Felissicimo (1996) afirma que o administrador público deve estar preparado para gerir não apenas uma situação, mas um processo permanente de mudança. Seguindo este pensamento, Souza (1998) defende que o administrador público deve atuar como um agente de mudanças nas organizações públicas atuais.

A importância do estágio obrigatório também foi destacada por autores como Felicissimo (1996), que afirma que, para a boa formação do administrador público, ele deve apresentar dotes pessoais, e estes devem ser desenvolvidos por meio de treinamento prático que ocorre na prática de estágio. Souza (1998) também destaca que, para a formação do administrador público, é importante o papel ocupado pelo estágio obrigatório, por possibilitar a maior integração com a máquina 
burocrática. Segundo a autora, este exercício prático deve ser fundamentado na ética e fornecer uma formação privilegiada a estes profissionais.

Desta forma, com base na bibliografia levantada, pode-se perceber a proximidade entre os autores pesquisados, no que está relacionado ao perfil e à formação do administrador público considerados como os mais adequados para que se tenha um serviço público mais eficiente e que garanta o bem-estar da população. $O$ conhecimento levantado pelos autores pode ser identificado nas disciplinas oferecidas pelos cursos de administração pública, para avaliar se há um alinhamento entre os currículos e o conhecimento considerado necessário. Sendo assim, os currículos de cursos de graduação e pós-graduação em administração pública no Brasil foram analisados para se identificar se existe este alinhamento.

\section{Metodologia}

A presente pesquisa caracteriza-se como de natureza qualitativa e de caráter descritivo, pois tem como objetivo a descrição dos currículos de cursos de graduação e pós-graduação em administração pública, bem como o estabelecimento de relações entre estes cursos e a literatura a respeito da formação do administrador público. Para tal, utiliza-se a técnica de pesquisa documental. Os dados coletados a respeito das instituições estudadas foram obtidos por meio da grade curricular e das ementas das disciplinas que compõem estas grades. As instituições de ensino superior que tiveram seus currículos analisados nesta pesquisa foram: os cursos de graduação em administração pública da Fundação Getúlio Vargas da Escola de Administração de Empresas de São Paulo (FGV/EAESP), da Fundação João Pinheiro, da Universidade de Brasília (UnB) e da Unisul; os cursos de pós-graduação da Fundação Getúlio Vargas da Escola Brasileira de Administração Pública e de Empresas (FGV/EBAPE), da Fundação João Pinheiro e da Escola Nacional de Administração Pública (ENAP). Os referidos cursos foram escolhidos como objeto de estudo, por comporem uma amostra heterogênea, que abrange cursos de graduação e de pós-graduação, bem como cursos de instituições públicas e privadas. As informações a respeito dos cursos podem ser observadas nos Quadros 3 e 4. 


\begin{tabular}{|c|c|c|c|}
\hline \multicolumn{4}{|c|}{ Cursos de graduação } \\
\hline Curso & $\begin{array}{c}\text { Carga } \\
\text { Horária } \\
\end{array}$ & $\begin{array}{l}\text { Natureza da } \\
\text { Instituição }\end{array}$ & $\begin{array}{c}\text { Outras Informações } \\
\text { Relevantes }\end{array}$ \\
\hline $\begin{array}{c}\text { Graduação em } \\
\text { Administração Pública } \\
\text { da FGV/EAESP }\end{array}$ & $\begin{array}{l}3.600 \text { horas e } \\
55 \text { disciplinas }\end{array}$ & Privada & $\begin{array}{l}\text { Constitui-se como uma das } \\
\text { linhas do curso de } \\
\text { administração da } \\
\text { instituição, juntamente com } \\
\text { a linha em Administração } \\
\text { de Empresas }\end{array}$ \\
\hline $\begin{array}{c}\text { Graduação em } \\
\text { Administração Pública } \\
\text { da Fundação João } \\
\text { Pinheiro }\end{array}$ & $\begin{array}{l}3.060 \text { horas, } \\
\text { com } 50 \\
\text { disciplinas }\end{array}$ & $\begin{array}{c}\text { Pública } \\
\text { estadual, } \\
\text { vinculada à } \\
\text { Secretaria de } \\
\text { Estado de } \\
\text { Planejamento } \\
\text { e Gestão de } \\
\text { Minas Gerais } \\
\end{array}$ & $\begin{array}{l}\text { É o único curso no País que } \\
\text { forma profissionais para } \\
\text { integrar a carreira de } \\
\text { Especialista em Políticas } \\
\text { Públicas e Gestão } \\
\text { Governamental do Poder } \\
\text { Executivo do Governo do } \\
\text { Estado de Minas Gerais. }\end{array}$ \\
\hline $\begin{array}{c}\text { Graduação em } \\
\text { Administração Pública } \\
\text { da UnB } \\
\end{array}$ & $\begin{array}{l}198 \text { créditos, } \\
\text { correspondentes } \\
\text { a } 41 \text { disciplinas }\end{array}$ & $\begin{array}{l}\text { Pública } \\
\text { federal }\end{array}$ & \\
\hline $\begin{array}{c}\text { Graduação Tecnológica } \\
\text { em Administração } \\
\text { Pública da Unisul } \\
\end{array}$ & $\begin{array}{l}1.620 \text { horas e } \\
27 \text { disciplinas }\end{array}$ & Privada & $\begin{array}{l}\text { Este se constitui em um } \\
\text { curso virtual }\end{array}$ \\
\hline
\end{tabular}

Quadro 4: Informações sobre os cursos de pós-graduação

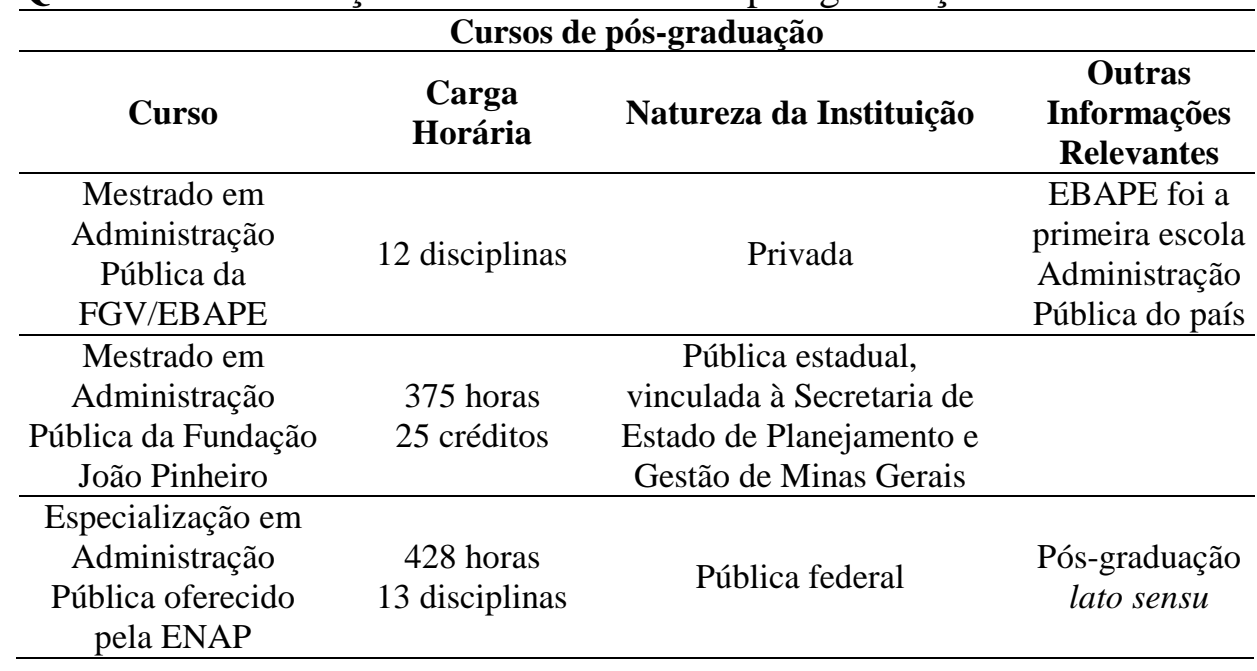

Os dados analisados na presente pesquisa foram coletados nos sites das instituições de ensino superior mencionadas anteriormente, por meio dos quais se teve acesso à grade curricular dos cursos objeto de 
análise, bem como às ementas das disciplinas que compõem essas grades. A análise dos dados foi realizada da seguinte maneira: com base na literatura especializada, foram estabelecidos campos de conhecimento passíveis de serem encontrados nos cursos de administração pública, quais sejam: política, direito, ética, administração de recursos, economia, gestão de pessoas, estratégia, finanças/contabilidade, negociação, estatística, teoria das organizações, administração internacional, cultura nacional, ciências sociais, democracia, inovação, gestão de mudanças, estágio e tecnologia/informática; foram identificados os campos de conhecimento que são abordados pelas disciplinas presentes nos cursos analisados; com base na análise do conteúdo das disciplinas, foram estabelecidas categorias de análise, que classificaram as disciplinas de cada curso; as áreas de conhecimento que se mostraram presentes no currículo dos cursos foram comparadas com as áreas de conhecimento levantadas na literatura; foram comparados os currículos para levantar suas similaridades e diferenças; uma nova análise de cada currículo foi feita com o objetivo de levantar as particularidades de cada um deles.

O método de pesquisa dotado foi a análise de conteúdo, a qual consiste em "um exercício de redução de dados onde o texto é codificado em determinadas categorias" (BAUER; GASKELL, 2002, p. 237). Para a análise dos dados presentes nos currículos e ementas dos cursos foi adotada uma grade aberta, identificando-se as categorias de análise conforme elas foram surgindo ao pesquisador. As categorias finais, que serviram de base para classificar conteúdo das disciplinas dos cursos são: 1) Políticas Públicas/Ciências Políticas; 2) Administração de Recursos/ Administração de Materiais; 3) Gestão de Pessoas/ Comportamento Organizacional/ Psicologia Organizacional; 4) Ciências Sociais; 5) Cultura Nacional; 6) História da Administração Pública Geral; 7) Administração Internacional/ Relações Internacionais; 8) Teorias Organizacionais/ Pensamento Organizacional; 9) Processo Decisório/ Tomada de Decisão; 10) Teorias Empreendedoras; 11) Planejamento das Organizações Públicas; 12) Qualidade e Produtividade do Serviço Público; 13) Administração Pública; 14) Planejamento Governamental; 15) Administração de Empresas Estatais; 16) Organização Governamental Brasileira; 17) Estratégia de Ensino; 18) Gestão Ambiental. Considerando-se que disciplinas com nomes semelhantes podem apresentar conteúdos diferentes, e que o contrário também é possível, os conteúdos abordados pelas disciplinas foram identificados por meio de suas ementas. 
Ressalta-se que a pesquisa tem como limitação o fato de ter pesquisado apenas alguns cursos de administração pública do Brasil e, seus resultados, portanto, não podem ser generalizados.

\section{APRESENTAÇ̃̃o dOS Resultados E ANÁLISES}

O Quadro 3 apresenta uma síntese da análise do currículo dos cursos e na sequência são apresentados os pontos principais resultantes.

O conteúdo referente ao direito é oferecido, quase sempre, em mais de uma disciplina, com as denominações de direito administrativo, fiscal, tributário, constitucional, fazendo-se a distinção entre o direito público e o privado na maior parte das instituições analisadas.

Com relação às disciplinas de economia, os cursos de graduação separam esta área em disciplinas de microeconomia, macroeconomia e economia do setor público ou economia brasileira. Outro ponto importante a ser aqui ressaltado é que todos os cursos têm suas disciplinas de economia aplicadas ao setor público, sendo denominadas, em sua maioria, por "economia do setor público".

Vale ressaltar as particularidades dos cursos. As disciplinas de marketing, por exemplo, que não foram abordadas por nenhum dos autores pesquisados, são oferecidas pelos cursos de graduação da FGV/EAESP, da Unisul e da Fundação João Pinheiro, bem como pelo mestrado da FGV/EBAPE. Pode-se ressaltar ainda que, em geral, esta disciplina tem seu conteúdo voltado para o setor público.

Como particularidade, ainda pode-se citar a grande ênfase dada à teoria empreendedora pelo curso de graduação da UnB, que oferece duas disciplinas obrigatórias que abordam o tema. Esta disciplina não é encontrada nos demais cursos. Já o curso de graduação da FGV/EAESP dá grande ênfase à questão da comunicação que foi ressaltada por alguns autores como um conhecimento muito relevante. O referido curso apresenta duas disciplinas que abordam o tema, sendo uma delas de aplicação direta às organizações públicas. Além disso, este curso é também o único a oferecer disciplina de logística, que, neste caso, também é de aplicação direta à área pública. O Quadro 5 apresenta uma comparação entre a estrutura dos cursos com a literatura especializada. 
Quadro 5: Disciplinas oferecidas pelos cursos em análise

\begin{tabular}{lcccccc} 
Disciplinas & EAESP FJP (G) & Unisul & UnB & EBAPE & ENAP & FJP \\
\hline
\end{tabular}

\begin{tabular}{llllllll}
\hline Políticas Públicas & $\mathrm{X}$ & $\mathrm{X}$ & $\mathrm{X}$ & $\mathrm{X}$ & $\mathrm{X}$ & $\mathrm{X}$ & $\mathrm{X}$ \\
\hline Direito & $\mathrm{X}$ & $\mathrm{X}$ & $\mathrm{X}$ & $\mathrm{X}$ & & & $\mathrm{X}$ \\
\hline
\end{tabular}

Ética

$\begin{array}{llll}\mathrm{X} & \mathrm{X} & \mathrm{X} \\ \mathrm{X} & \mathrm{X} \\ \mathrm{X} & \mathrm{X} & \mathrm{X}\end{array}$

Adm de Rec.

\begin{tabular}{llllllll}
\hline Gestão Pessoas $^{2}$ & $\mathrm{X}$ & $\mathrm{X}$ & $\mathrm{X}$ & $\mathrm{X}$ & $\mathrm{X}$ & $\mathrm{X}$ & \\
\hline Finanças & $\mathrm{X}$ & $\mathrm{X}$ & $\mathrm{X}$ & $\mathrm{X}$ & $\mathrm{X}$ & $\mathrm{X}$ & $\mathrm{X}$ \\
\hline Economia & $\mathrm{X}$ & $\mathrm{X}$ & $\mathrm{X}$ & $\mathrm{X}$ & $\mathrm{X}$ & & $\mathrm{X}$ \\
\hline Contabilidade & $\mathrm{X}$ & $\mathrm{X}$ & $\mathrm{X}$ & $\mathrm{X}$ & & & \\
\hline Ciências Sociais & $\mathrm{X}$ & $\mathrm{X}$ & $\mathrm{X}$ & $\mathrm{X}$ & & & \\
Cultura Nacional $^{3}$ & $\mathrm{X}$ & $\mathrm{X}$ & & & & & $\mathrm{X}$ \\
\hline Hist. Ad. Pub. $^{3}$ & & & $\mathrm{X}$ & & & &
\end{tabular}

\begin{tabular}{lccccccc}
\hline Adm Int. & \multicolumn{1}{l}{} & $\mathrm{X}$ & & & & & \\
\hline Inovação & $\mathrm{X}$ & & & & $\mathrm{X}$ & & \\
\hline Tecnologias & $\mathrm{X}$ & $\mathrm{X}$ & $\mathrm{X}$ & $\mathrm{X}$ & $\mathrm{X}$ & $\mathrm{X}$ & $\mathrm{X}$ \\
\hline Matemática & $\mathrm{X}$ & $\mathrm{X}$ & $\mathrm{X}$ & $\mathrm{X}$ & & & \\
\hline Estatística & $\mathrm{X}$ & $\mathrm{X}$ & & $\mathrm{X}$ & $\mathrm{X}$ & & \\
\hline T.O. & & $\mathrm{X}$ & & $\mathrm{X}$ & $\mathrm{X}$ & & $\mathrm{X}$ \\
\hline Estratégia & & $\mathrm{X}$ & & $\mathrm{X}$ & & & \\
\hline Estágio & $\mathrm{X}$ & $\mathrm{X}$ & & $\mathrm{X}$ & & & \\
\hline Negociação & & & $\mathrm{X}$ & & & & \\
\hline Metodologia & & $\mathrm{X}$ & & $\mathrm{X}$ & $\mathrm{X}$ & $\mathrm{X}$ & $\mathrm{X}$ \\
\hline Proc. Dec. & $\mathrm{X}$ & & & $\mathrm{X}$ & $\mathrm{X}$ & & \\
\hline Projetos & $\mathrm{X}$ & $\mathrm{X}$ & & & & $\mathrm{X}$ & $\mathrm{X}$ \\
\hline Comunicação & $\mathrm{X}$ & & & & & & \\
\hline Marketing & $\mathrm{X}$ & $\mathrm{X}$ & $\mathrm{X}$ & & $\mathrm{X}$ & & \\
\hline Teoras & & & & $\mathrm{X}$ & & & \\
\hline
\end{tabular}

Teorias

Empreendedoras

$\mathrm{X}$

\begin{tabular}{|c|c|c|c|c|c|c|c|}
\hline Gestão Pública & $\mathrm{X}$ & $\mathrm{X}$ & & & & $\mathrm{X}$ & $\mathrm{X}$ \\
\hline P. Org. Pub. ${ }^{7}$ & $\mathrm{X}$ & & & & & & \\
\hline Qual. S. Pub. ${ }^{8}$ & $\mathrm{X}$ & & & & & & \\
\hline Administração Pública & $\mathrm{X}$ & $\mathrm{X}$ & & $\mathrm{X}$ & & $\mathrm{X}$ & \\
\hline P. Gorvern. ${ }^{9}$ & & $\mathrm{X}$ & $\mathrm{X}$ & $\mathrm{X}$ & $\mathrm{X}$ & & $\mathrm{X}$ \\
\hline A. Emp. Est. ${ }^{10}$ & & & $\mathrm{X}$ & $\mathrm{X}$ & & & \\
\hline O. Gov. Bras. ${ }^{I I}$ & & & & $\mathrm{X}$ & $\mathrm{X}$ & & \\
\hline Estratégias de Ensino & & & & & $\mathrm{X}$ & & \\
\hline Gestão Ambiental & & & & & $\mathrm{X}$ & & \\
\hline Regulação & & $\mathrm{X}$ & & & $\mathrm{X}$ & & $\mathrm{X}$ \\
\hline
\end{tabular}

Legenda: 1. Administração de Recursos/Administração de Materiais; 2. Comportamento Organizacional/Psicologia Organizacional; 3. História da Administração Pública; 4. Administração Internacional/Relações Internacionais; 5. Teorias Organizacionais/ Pensamento Organizacional; 6. Processo Decisório/Tomada de Decisão; 7. Planejamento das Organizações Públicas; 8. Qualidade e Produtividade do Serviço Público; 9. Planejamento Governamental; 10. Administração de Empresas Estatais; 11. Organização Governamental Brasileira. 


\section{Análise Curricular}

A revisão bibliográfica revelou um consenso entre os autores com relação à enorme importância do conhecimento político por parte do administrador público atual. Isso se justificou pelo fato de as organizações públicas serem espaços marcados por conflitos políticos e constante incerteza, como ressaltado por Souza (2002) e Pereira (2009). Sendo assim, após a análise curricular dos cursos anteriormente destacados, observou-se a presença de disciplinas que abordam políticas públicas e/ou ciências políticas em todos os cursos analisados. Os cursos de graduação incluem mais de uma disciplina com esse mesmo enfoque, e alguns ainda são mais específicos ao dedicarem uma disciplina à política brasileira.

Com relação às disciplinas de direito, que também foram ressaltadas por autores como Newcomer (1999) e Duque (2006), elas mostraram-se presentes na maioria dos cursos de graduação analisados. Porém, neste ponto marca-se uma diferença entre os cursos de graduação com relação aos de pós-graduação. Estes últimos quase não apresentam disciplinas de direito. Desta forma, enquanto os cursos de graduação dão grande ênfase ao direito, apresentando um currículo completo neste sentido, os cursos de pós-graduação se distanciam da teoria, neste ponto, ao restringirem o espaço a esta área.

A necessidade de conhecimento de ética foi muito ressaltada por vários autores, tanto ao traçarem o perfil do administrador público como ao destacarem as disciplinas que deveriam fazer parte de sua formação. Autores que dão bastante ênfase a esta questão são Dror (1997), Pereira (2009) e Newcomer (1999), que destacam a perda de legitimidade por parte do governo para justificar esta importância. Porém, os cursos analisados não correspondem à literatura neste ponto que, para os autores, se mostra tão relevante. Como pode ser observado no Quadro 5, são poucos os cursos que apresentam a referida disciplina. Sendo assim, este é um ponto de distanciamento com relação à literatura.

No que diz respeito à administração de recursos, autores como Duque (2006), Newcomer (1999) e Felissicimo (1996) a destacam como de extrema relevância, já que as organizações públicas lidam com escassez de recursos. A este respeito, entre os cursos de graduação analisados, poucos apresentam a disciplina. Já entre os cursos de pósgraduação, nenhum apresenta disciplinas que tratem deste tema, como pode ser observado no Quadro 5. Assim, mais uma vez, os cursos analisados vão de encontro à teoria. 
Outra área de grande destaque na literatura foi gestão de pessoas, que foi citada por muitos autores como Penengo (1997), Souza (2002), Keinert (1996), Newcomer (1999) e Ferrarezi e Zimbrão (2005). Neste sentido, os cursos analisados também seguem este pensamento, apresentando, quase sempre, disciplinas de gestão de pessoas. Os cursos de graduação se diferenciam dos de pós-graduação neste ponto, por darem maior ênfase à referida disciplina, apresentando, em sua maioria, disciplinas de psicologia das organizações, além da disciplina específica de gestão de pessoas.

Conhecimento na área financeira e economia também foi citado entre os autores, apesar de não ter sido tão enfatizado. A este respeito, todos os cursos analisados apresentam disciplinas que abordam os temas. Porém, os cursos de graduação dão ênfase muito grande a estes campos de conhecimento, apresentando pelo menos três disciplinas que tratem do tema, enquanto os cursos de pós-graduação apresentam apenas uma, e nem sempre obrigatória. A disciplina de finanças aplicada à gestão pública também aparece em alguns casos.

No que diz respeito ao conhecimento de contabilidade e ciências sociais, ressaltado na literatura, também se destaca uma diferença entre os cursos de graduação com relação aos de pós-graduação. As referidas disciplinas não são oferecidas por nenhum dos cursos de pós-graduação, mas se encontra presente em todos os cursos de graduação analisados, como apresenta o Quadro5. Este marca mais um ponto de distinção entre os cursos de graduação e os de pós.

Outro ponto que distancia os cursos de graduação daqueles de pósgraduação diz respeito à disciplina de matemática. Tal disciplina se mostrou presente em todos os cursos de graduação analisados, em alguns casos com mais de uma disciplina, porém está ausente em todos os cursos de pós-graduação.

Autores como Duque (2006) e Ferrarezi e Zimbrão (2005) destacaram ainda a importância de conhecimento referente à cultura nacional, que é abordada em poucos cursos, como mostra o Quadro 5. Isto revela mais um ponto de distanciamento entre a teoria e a prática da formação do administrador público.

Newcomer (1999) defende que o administrador público deve ter conhecimento da história de sua profissão para que possa valorizá-la e exercê-la com dignidade. Este tema é abordado apenas pela Unisul que oferece uma disciplina denominada "História da Administração Pública Brasileira". 
Outro campo de conhecimento bastante destacado pelos autores estudados foi a área de relações internacionais, baseada no conhecimento dos sistemas internacionais, e a abordagem de temas como a globalização. Este aspecto foi levantado por autores como Penengo (1997) e Duque (2006). Porém, este tipo de abordagem não esteve muito presente, como revela o Quadro 5.

Muitos autores, entre eles Amaral (2006), Felicíssimo (1996) e Gomes (2008), levantaram a importância de conhecimento de inovação por parte dos administradores públicos, já que se vive hoje um contexto de constante mudança. Porém, este constitui mais um ponto de forte divergência com relação à literatura. Mais uma vez, apenas o curso de graduação da FGV/EAESP e o mestrado da FGV/EBAPE abordam diretamente o tema em disciplinas oferecidas, como pode ser observado no Quadro 5.

Diretamente ligado à inovação, encontra-se o domínio de novas tecnologias. Autores como Souza (2002), Duque (2006), Pacheco (2000) e Gomes (2008) defendem a importância do conhecimento de informática e tecnologia por parte dos administradores públicos. Neste ponto, os cursos analisados correspondem ao levantamento bibliográfico realizado, por apresentarem, em todos eles, disciplinas relativas à gestão de informação ou de novas tecnologias.

O domínio de estatística foi ressaltado por Newcomer (1999) e Duque (2006) como relevante para a formação deste profissional. A este respeito, a referida disciplina está presente na maioria dos cursos de graduação. Porém, a disciplina está ausente em todos os cursos de pósgraduação analisados, excetuando-se apenas o da FGV/EBAPE, como mostra o Quadro 5. Este pode ser levantado como mais um ponto que diferencia os cursos de graduação daqueles de pós-graduação.

A disciplina referente às teorias das organizações foi bastante ressaltada por Duque (2006). Mas, mostrou-se presente apenas nos cursos de graduação da UnB e da Fundação João Pinheiro. Já no que diz respeito aos cursos de pós-graduação, só não é oferecida pela especialização da ENAP, sendo disciplina obrigatória nos demais.

Autores como Souza (2002), Felissicimo (1996) e Newcomer (1999) destacaram ainda o conhecimento de estratégia como relevante para a formação do administrador público. Porém, disciplinas que abordam diretamente o tema não se mostraram muito presentes, como pode ser observado no Quadro 5.

Pode-se citar ainda a disciplina de estágio obrigatório, que foi bastante ressaltada por Souza (1998) e Felissicimo (1996), como de 
extrema importância para que o futuro administrador público se desenvolva na prática. A referida disciplina é oferecida pelo curso de graduação da FGV/EAESP, Fundação João Pinheiro e UnB, como apresentado no Quadro 5.

O conhecimento de negociação, ressaltado por vários autores, só se apresenta no curso de graduação da Unisul, com a denominação "Conflito, Negociação e Processo Decisório", como mostra o Quadro 5. Já a disciplina de Gestão de mudanças, muito enfatizada por inúmeros autores, devido ao momento de incertezas que se tem hoje, não é oferecida por nenhum dos cursos analisados.

A importância de se estabelecer a diferenciação entre a administração de empresas e a administração pública, bem como a diferenciação de suas ferramentas, ressaltada por Newcomer (1999) e Nicolini (2008) mostrou-se presente. Os cursos analisados fazem esta diferenciação, oferecendo disciplinas aplicadas diretamente ao setor público. Isto pode ser observado principalmente nos cursos de pósgraduação. Já nos cursos de graduação, esta diferenciação nem sempre se apresenta, principalmente nas matérias introdutórias. Entretanto, pode-se perceber a ausência de distinção entre as áreas pública e privada, fato combatido pelos autores, no que diz respeito, por exemplo, à adoção de disciplinas que têm origem na administração de empresas, como é o caso das disciplinas de gestão de pessoas ou marketing, por exemplo. Tal fenômeno pode ser decorrência da disseminação da lógica gerencial, que se deu na administração pública, no fim do século XX. Embora tais disciplinas sejam importantes, é preciso que as peculiaridades do setor público sejam consideradas ao abordá-las, como defendem Newcomer (1999) e Nicolini (2008).

Baseado no Quadro 5 pode-se observar a presença de disciplinas sobre planejamento governamental, administração pública e gestão pública em alguns dos cursos analisados, marcando este direcionamento dos cursos ao setor público, como defende a literatura especializada. A presença de disciplinas como "Organização Governamental Brasileira" e "Qualidade e Produtividade do Setor Público", em alguns cursos, também vai ao encontro deste ponto destacado.

É ainda possível observar pontos em comum entre os cursos analisados, mas que não foram abordados pela literatura levantada. Disciplinas referentes à metodologia de pesquisa estão presentes em quase todos os cursos de pós-graduação analisados, como mostra o Quadro 5. Apesar de presente na formação do administrador público, a referida disciplina não foi abordada pelos autores pesquisados. 
Outra área que segue este mesmo padrão é a área de projetos. Disciplinas referentes a projetos podem ser encontradas em todos os cursos de pós-graduação analisados, e em grande parte dos cursos de graduação. Alguns cursos oferecem mais de uma disciplina obrigatória abordando o tema. Sendo assim, este é um conhecimento considerado importante pelas instituições de ensino superior analisadas, mas que não foi ressaltado pela literatura. $\mathrm{O}$ mesmo ocorre com as disciplinas de matemática presentes nos cursos de graduação.

Desta forma, os cursos levantados podem ser considerados bastante homogêneos no que diz respeito ao currículo utilizado na formação dos administradores públicos. Porém, em muitos pontos estão distantes do que é defendido pelos autores que abordam este tema. Instituições privadas e públicas também não apresentaram diferenças relevantes em seus currículos. Mas, no que diz respeito à distinção entre os cursos de graduação e os de pós-graduação, algumas diferenças foram observadas: as disciplinas de direito são muito menos exploradas pelas pós-graduações; as áreas de administração financeira e de economia não recebem tanta ênfase pelos cursos de pós-graduação; o mesmo ocorre com as disciplinas de contabilidade, matemática, estatística e de áreas sociais. Vale ressaltar, entretanto, que tais diferenças podem ser explicadas pelo fato de os cursos de pós-graduação adotarem uma grade com disciplinas mais específicas, diretamente relacionadas com a linha de pesquisa estudada, como mostraram Martins (2000) e Balbachevzky (2005).

Desta forma, pode-se inferir, com base na análise curricular, que os cursos de graduação e pós-graduação em administração pública, oferecidos pelas instituições de ensino superior brasileiras, ora abrangidas pelo estudo, possuem muitos pontos de convergência com a teoria, contribuindo, assim, para a boa formação do administrador público atual. Pode-se citar entre eles, a presença de disciplinas que abordam a política, a gestão de pessoas, a administração financeira, a economia e as novas tecnologias, que são ressaltadas pelos autores e estão presentes nos currículos analisados. Porém, estes cursos também apresentam alguns pontos de divergência com os autores pesquisados. Isto se observa na ausência de disciplinas sobre ética, relações internacionais, inovação, gestão de mudanças, entre outras, que foram defendidas na literatura como de fundamental importância na formação deste profissional. Estes pontos de divergência devem servir como impulsionadores de discussões e reflexões sobre a formação do administrador público, que é oferecida atualmente. 


\section{CONSIDERAÇÕES FINAIS}

A pesquisa aqui apresentada foi realizada com o objetivo de identificar em que pontos os cursos de graduação e pós-graduação em administração pública, oferecidos por instituições de ensino superior brasileiras, atendem ao perfil desejado do administrador público presente na literatura oferecendo, assim, insumos para uma reflexão a respeito destes currículos.

A literatura especializada contribuiu com muitos dados a respeito da formação mais adequada do administrador público, sempre levando em conta o contexto atual em que este profissional estará inserido. Parece haver consenso entre os autores com relação à importância de conhecimento político na formação do administrador público, juntamente com o conhecimento técnico habitualmente oferecido. Isto possibilita a formação mais ampla destes profissionais, tornando-os aptos a atuar em ambientes de conflitos e incertezas. Outros pontos também muito ressaltados foram gestão de pessoas, ética, administração de recursos e inovação.

Os cursos, objeto desta análise, foram os de graduação em administração pública da FGV/EAESP, da Fundação João Pinheiro, da Unisul e da UnB, e os cursos de pós-graduação da FGV/EBAPE, da Fundação João Pinheiro e da ENAP. Os dados coletados foram referentes às grades curriculares dos referidos cursos, bem como às ementas de suas disciplinas, disponíveis nos sites destas instituições.

Como principais resultados obtidos, citam-se a correspondência dos currículos analisados com a literatura levantada no que diz respeito à presença de disciplinas referentes à política, gestão de pessoas, administração financeira, economia e às novas tecnologias, revelando a boa formação oferecida ao administrador público atualmente. Além disso, também se evidenciou o distanciamento entre currículos de graduação e os de pós-graduação, notando-se a maior especificidade dos cursos de pós-graduação. Esta constatação confirma as observações de Martins (2000) e Balbachevsky (2005), que mostram que os cursos de pósgraduação possuem a tendência de serem mais especialistas, apresentando disciplinas diretamente relacionadas à sua linha de pesquisa. Também, destacou-se a divergência deste currículo com relação à bibliografia pesquisada no que se refere às disciplinas de ética, administração de recursos, relações internacionais, inovação, estratégia, gestão de mudanças, entre outras. 
É importante enfatizar que os resultados deste estudo não podem ser indistintamente generalizados, já que não foram analisados todos os cursos de administração pública do País.

Foi possível observar a relevância da boa formação do administrador público para o desenvolvimento do País. Espera-se que os pontos de divergência aqui levantados possam servir de base para futuras discussões a respeito da formação, que vem sendo oferecida ao administrador público atual, para que esta possa ser aprimorada. Desta forma, trabalhos futuros podem ser realizados no sentido de analisar outros cursos de administração pública que não foram aqui abordados, podendo inclusive ser comparados com o ensino de administração pública em outros países para que se amplie esta discussão.

\section{REFERÊNCIAS}

AMARAL, H. K. Desenvolvimento de competências de servidores na administração pública brasileira. Revista de Serviço Público, ano 57, n. 4, p. 549-563, 2006.

BALBACHEVSKY, E. A pós-graduação no Brasil: novos desafios para uma política bem-sucedida. In: BROCK. C.; SCHWARTZMAN, S. Os desafios da educação no Brasil. Rio de Janeiro: Nova Fronteira, 2005.

BAUER, M. W.; GASKELL, G. Pesquisa qualitativa como texto, imagem e som: um manual prático. 3.ed. Petrópolis: Vozes, 2002.

BRASIL. Lei $n^{\circ} 8.112$, de 11 de dezembro de 1990. Dispõe sobre o regime jurídico dos servidores públicos civis da União, das autarquias e das fundações públicas federais. Subsecretaria de Assuntos Jurídicos, Brasília, DF, Publicação Consolidada da Lei n ${ }^{\circ} 8.112$, de 11 de dezembro de 1990, Determinada pelo Art. 13 da Lei $\mathrm{n}^{\circ}$ 9.527, de 10 de dezembro de 1997.

DALLARI, A. O Que é Funcionário Público. São Paulo: Brasiliense, 1989.

DIAS, T. L. Modelo de sistemas viáveis em organizações públicas: um estudo de caso da função de planejamento de informações estratégicas para informatização da Secretaria Municipal de Saúde de Belo Horizonte. 1998, 146 f. Dissertação (Mestrado) — Escola de Governo, Fundação João Pinheiro, Belo Horizonte, 1998. In: PIRES, J. C. S.; MACÊDO, K. B. Cultura organizacional em organizações públicas no Brasil. Revista de Administração Pública, v. 40, n. 1, p. 81-105, 2006. 
DROR, Y. O administrador público tipo delta para o século 21. Revista do Serviço Público, Ano 48, n. 2, p. 5-26, 1997.

DUQUE, F. El gerente público: un profissional indispensable para el desarollo. Cadernos EBAPE,v. 4, n. 4, p. 113-154, 2006.

KEINERT, T. M. M. Os paradigmas da administração pública no Brasil (1990-92). Revista de Administração de Empresas, São Paulo, v. 34, n. 3, p. 41-48, 1994. In: FELICISSIMO, J. R. A formação de recursos humanos para o governo: algumas questões e a experiência recente da FUNDAP. Cadernos Fundap, n. 21, p. 198-215, 1996.

FELICISSIMO, J. R. A formação de recursos humanos para o governo: algumas questões e a experiência recente da FUNDAP. Cadernos Fundap, n. 21, p. 198-215, 1996.

FERRAREZI, E.; ZIMBRÃO, A. Formação de carreiras para a gestão pública contemporânea: o caso dos especialistas em políticas públicas e gestão governamental. In: X Congreso Internacional Del Clad Sobre La Reforma Del Estado Y De La Administración Pública, Santiago, Chile, 18-21 Out. 2005.

GAETANI, F.O ensino de administração pública no Brasil em um momento de inflexão. Revista de Serviço Público, ano 50, n. 4, p. 92-120, 1999.

GOMES, M. T. S. Formação dos dirigentes de administração pública para a governança: o contributo possível das tecnologias. In: XII Congreso Internacional Del Clad Sobre La Reforma Del Estado Y De La Administración Pública, Buenos Aires, Argentina, 4-7 nov. 2008.

KEINERT, T. M. M. Análise das propostas dos cursos de administração pública no Brasil em função da evolução do campo de conhecimento. São Paulo: EAESP/ FGV-NPP, 1996.

MARTINS, C. B. O ensino superior brasileiro nos anos 90. São Paulo em Perspectiva, v. 14, n. 1, p. 41-60, 2000.

MELO, M. C. O.; CKAGNAZAROFF, I. B.; TEODÓSIO, A. S. S.

Parceria: novas exigências para os gerentes do setor público e desafios para a sua formação. In: I Encontro Nacional de Estudos Organizacionais, 2000, Curitiba. Anais... Curitiba: Eneo, 2000.

NEWCOMER, K. E. A preparação dos gerentes públicos para o século XIX. Revista do Serviço Público, ano 50, n. 2, p. 5-18, 1999. 
NICOLINI, A. M. A Escola Nacional de Administração Pública: uma universidade corporativa do Estado brasileiro? In: XII Congreso Internacional Del Clad Sobre La Reforma Del Estado Y De La Administración Pública, Buenos Aires, Argentina, 4-7 nov. 2008.

OLIVEIRA, J. L.; PEREIRA, D. C.; RAMIREZ, R. M. O Perfil do Profissional de Administração: As Organizações com a Palavra. Caderno de Administração, v. 2, n. 2, p. 5-55, 1995.

PACHECO, R. S. Escolas de governo: tendências e desafios: ENAPBrasil em perspectiva comparada. Revista do Serviço Público, ano 51, n. 2, p. 35-53, 2000.

PENENGO, M. O papel do gerente público em processos de mudança. Revista do Serviço Público, ano 48, n. 1, p. 79-89, 1997.

PEREIRA, L. C. B. Construindo o Estado republicano: democracia e reforma da gestão pública. Rio de Janeiro: FGV, 2009.

PIRES, J. C. S.; MACÊDO, K. B. Cultura organizacional em organizações públicas no Brasil. Revista de Administração Pública, v. 40, n. 1, p. 81-105, 2006.

SOUZA, E. C. L. Políticas públicas: formação de gestores governamentais em tempos de mudança. Revista Brasileira de Estudos Pedagógicos, v. 79, n. 191, p. 42-81, 1998.

SOUZA, E. C. L. A capacitação administrativa e a formação de gestores governamentais. Revista de Administração Pública, v. 36, n. 1, p. 73-88, 2002.

WEBER, M. Economia e sociedade: fundamentos da sociologia compreensiva. Brasília: Universidade de Brasília, 1999. 
DAdOS DOS Autores

VANESSA BRUlon SoARES (vanessabrulon@gmail.com)

Mestre em Administração Pública pela FGV/EBAPE

Instituição de vinculação: Fundação Getulio Vargas - Escola Brasileira de Administração Pública e de Empresas

Rio de Janeiro/RJ

Áreas de interesse em pesquisa: Teoria das Organizações e Administração Pública.

Pierre Ohayon (pohayon@ facc.ufrj.br)

Doutor em Administração de Empresas pela FEA/USP

Instituição de vinculação: Faculdade de Administração e Ciências Contábeis - Universidade Federal do Rio de Janeiro

Rio de Janeiro/RJ

Áreas de interesse em pesquisa: Avaliação em Ciência e Tecnologia.

GERSON ROSENBERG (gerson@fiocruz.br)

Doutor em Tecnologia de Processos Químicos e Bioquímicos pela UFRJ Instituição de vinculação: Fundação Oswaldo Cruz

Rio de Janeiro/RJ

Áreas de interesse em pesquisa: Gestão da Inovação e Gestão Pública

Recebido em: 13/08/2010 • Aprovado em: 25/02/2011

* O presente trabalho foi realizado com o auxílio financeiro da Fundação Carlos Chagas Filho de Amparo à Pesquisa do Estado do Rio de Janeiro (FAPERJ) concedido para a realização da pesquisa. 